Semin Arthritis Rheum. 2011 February ; 40(4): 324-329. doi:10.1016/j.semarthrit.2010.03.004.

\title{
More than meets the eye
}

\author{
Rebecca L. Manno, MD, Stuart M. Levine, MD, and Allan C. Gelber, MD \\ Division of Rheumatology, Johns Hopkins University School of Medicine
}

\begin{abstract}
Rheumatologists take great pride in making elegant diagnoses. We carefully assess seemingly disparate signs and symptoms and use these clinical clues to make diagnoses based on predictable disease phenotypes. However, few clinical features of rheumatic disease are unique to a single disease process. Here we describe a case where the overlap of clinical features led to an initially broad differential diagnosis of seemingly unrelated diseases. Ultimately, the discovery of a radiographic finding allowed us to more clearly define the diagnosis, make inferences regarding the underlying pathophysiology, and intervene therapeutically with the goal of averting potentially significant morbidity.
\end{abstract}

\section{CASE REPORT}

A 27-year-old African American woman was admitted to the Johns Hopkins Hospital with fever and visual changes. She had been well until nine months earlier when she developed unilateral blurry vision in the left eye. The symptoms persisted, and she sought the care of an ophthalmologist. Examination at that time revealed bilateral acute anterior uveitis. She was treated with topical steroids and her vision returned to baseline.

Over the next few months, however, she developed debilitating fatigue and experienced an unintentional fifteen pound weight loss. One month prior to presentation, she noted the onset of daily low grade fevers and chills. On the day of admission, she developed a temperature of $103^{\circ} \mathrm{F}$ and a severe frontal headache. Her past medical history was notable for new-onset headaches that developed 18 months prior and were diagnosed as migraines. She worked as an engineer and had no history of alcohol, drug or tobacco use, or foreign travel. There was no family history of autoimmune disease. Review of systems was notable for the absence of Raynaud's, rash, chest pain, cough, shortness of breath, and change in mental status. She noted diffuse arthralgias of her hands and lower back, although she denied the presence of swollen joints.

On examination, the patient was a well-developed, well-nourished African-American woman. Although clearly uncomfortable, she was alert, fully oriented, and insightful. Temperature was $103^{\circ} \mathrm{F}$. Blood pressure in the right arm was $97 / 62 \mathrm{mmHg}$; a blood pressure could not be measured in the left arm. Brachial and radial artery pulses were palpable and seemingly symmetric bilaterally. No carotid or subclavian bruits were auscultated. There were no oropharyngeal ulcers, and her conjunctivae were clear. Fundoscopic examination revealed normal optic discs without papilledema, retinal hemorrhages or exudates. Slit lamp examination revealed $1+$ cell and flare in the anterior chambers in the right eye and $2+$ in the left. Musculoskeletal exam revealed no synovitis or joint deformities. Nailfold capillary

Address correspondence to: Allan C. Gelber, MD, Johns Hopkins University School of Medicine, 5200 Eastern Avenue, Mason F. Lord Building, Center Tower, Suite 4100, Baltimore, MD 21224, agelber@jhmi.edu, Phone: 410-550-2018, Fax: 410-550-2072. 
microscopy was normal. Neurologic exam demonstrated preserved strength in all upper and lower extremity muscle groups with normal bulk and tone.

Laboratory data revealed a white-cell count of 3900 cells $/ \mathrm{mm}^{3}$ with a normal differential, hemoglobin was $10.6 \mathrm{~g} / \mathrm{dL}$, hematocrit was $31.5 \%$, and platelet count $245,000 / \mathrm{mm}^{3}$. Serum electrolyte levels, liver-function tests, complement levels and urinalysis were within normal limits. Total protein was $6.1 \mathrm{~g} / \mathrm{dL}$ and albumin $3.1 \mathrm{~g} / \mathrm{dL}$. The erythrocyte sedimentation rate was elevated at $73 \mathrm{~mm} /$ hour and the C-reactive protein level was also high at $8.2 \mathrm{mg} / \mathrm{dl}$. Lumbar puncture showed $2 \mathrm{WBC} / \mathrm{hpf}, 0 \mathrm{RBC} / \mathrm{hpf}$, a normal protein at $19 \mathrm{mg} / \mathrm{dl}$, and negative Gram stain and culture. Antinuclear, anti-double stranded DNA, and antineutrophilic cytoplasmic antibodies were all negative, as were HLA B27 antigen, rheumatoid factor, and RPR. ELISA for Lyme disease, HIV, hepatitis C, hepatitis B, and tuberculin skin testing were all unrevealing. Chest and lumbosacral spine X-rays were normal. Computed tomography (CT) of the head was negative. In the setting of this largely unrevealing work-up for an etiology of her uveitis and fever, CT imaging of the chest was obtained. Whereas no adenopathy or pulmonary infiltrates were seen, bilateral carotid arterial thickening was noted (Figure 1). Magnetic resonance imaging (MRI) confirmed the CT findings, revealing circumferential thickening of the aortic arch and great vessels without focal stenosis (Figure 2). These findings were diagnostic of aortitis.

\section{DISCUSSION}

This 27 year old woman, who initially presented with bilateral uveitis, proceeded to develop systemic inflammatory symptoms, persistent fevers, and ultimately a large vessel vasculitis. Were there any clues during her clinical course that could have predicted her ultimate diagnosis?

In a cohort of 1916 patients with uveitis, the most frequent systemic disease associations were the seronegative spondyloarthropathies (13.4\%) (predominantly ankylosing spondylitis), sarcoidosis (4.5\%), multiple sclerosis (3.1\%), and Behcet's syndrome (1.8\%). Indeed, systemic inflammatory disorders as a group were more common etiologies than infectious diseases, such as Lyme disease (12\%) (1). Therefore, patients presenting with bilateral uveitis should be evaluated for the presence of systemic inflammatory processes, particularly in the context of arthritis and fever (2). These patients should be referred by the treating ophthalmologist to a rheumatologist for evaluation of a potential underyling immune-mediated multisystem rheumatic disorder (Figure 3) (3). However, our patient did not have any other localizing symptoms suggestive of a systemic process on her initial uveitis episode, contributing to the elusive nature of her underlying disease process.

When our patient re-presented with fever, arthalgias, unintentional weight loss and headache, CT imaging was appropriately pursued as part of the work-up for fever of unknown origin (FUO), yielding the discovery of aortitis and carotid arterial thickening. Importantly, the differential diagnosis for uveitis and concomitant aortitis narrows the differential diagnosis to a group of diseases (Table 1), which were considered in this case.

Lyme disease and tuberculosis as potential infectious etiologies were quickly ruled out with negative serology, normal cerebrospinal fluid, negative PPD, and lack of tick exposure or foreign travel. Syphilis was also considered unlikely in this case with a negative RPR; however, this spirochetal infection should be considered carefully in the context of uveitis and aortitis. Ocular findings occur in $\sim 10 \%$ of patients with syphilis, among whom uveitis is the most common eye manifestation (4). Syphilitic uveitis is varied and can occur in the secondary or latent stage of the infection, involve the anterior or posterior segment of the uveal tract, and can be unilateral or bilateral (4). Syphilitic aortitis most frequently involves 
the aortic arch and thoracic aorta and can lead to aortic rupture, aortic regurgitation, and heart failure (5). Although in 2000 the overall incidence of syphilis was the lowest it has been since 1941, it remains a significant public health concern today. The Centers for Disease Control report that between 2005 and 2006 the total number of syphilis cases in the United States increased by $11 \%$, with the highest incidence of primary and secondary infection occurring among women age 20-24 years and in men 35-39 years of age (6). Hence, it is important to maintain a high index of suspicion for syphilis when a patient presents with multi-system inflammatory signs and symptoms, particularly the cooccurrence of uveitis and aortitis. In our case, the negative RPR and negative sexual exposure effectively ruled out this consideration.

Spondyloarthropathy was considered unlikely given the normal sacroiliac joint imaging and negative HLA B27 status. There were no oral or genital ulcerations to support a diagnosis of Behcet's syndrome, and her lumbar puncture results ruled out aseptic meningitis.

Sarcoidosis, Crohn's disease, rhinogenic granulomatosis with necrotizing angiitis (7) and Takayasu arteritis remained diagnostic considerations, given the rare reported associations of uveitis and aortitis in each of these granulomatous disease processes (8-14).

Several case reports and small case series describe the association of large vessel vasculitis with sarcoidosis (8). Uveitis is described in a number of these patients, who frequently present with ocular inflammation, then develop aortitis later in their course $(8,9)$. However, the lack of hilar adenopathy, pulmonary infiltrates, erythema nodosum, or inflammatory arthritis makes sarcoidosis an unlikely unifying diagnosis in this case.

Crohn's disease is an inflammatory granulomatous condition of the gastrointestinal tract characterized by transmural inflammation and fistula formation. Ocular complications of Crohn's, including conjunctivitis, blepharitis and uveitis are common; the latter occuring in $\sim 5 \%$ of patients (10). In addition, vascular complications have been reported in $1.3 \%$ of patients with inflammatory bowel disease, with thromboembolic disease being most common (11). Notably, medium and large vessel vasculitis has also been described in patients with inflammatory bowel disease $(11,12)$. In several cohort studies of Takayasu arteritis, the reported frequency of associated Crohn's disease ranged from 3-9\% $(9,12-14)$. In our case, the lack of GI symptoms, peripheral arthritis, or skin lesions made Crohn's disease unlikely. Genotyping for CARD15/NOD2 mutation, which confers susceptibility for inflammatory bowel disease, was not obtained in this case $(15,16)$. However, the inclusion of this test would be a reasonable diagnostic strategy in the evaluation of a patient with uveitis and gastrointestinal symptoms.

The ANCA-associated vasculitides encompass a number of distinct disorders, characterized by pulmonary capillaritis, glomerulonephritis, and inflammation of the sinonasal and upper respiratory passages. For example, rhinogenic granulomatosis with necrotizing anigiitis, in whom most patients are seropositive for c-ANCA and display high levels of anti-proteinase 3 antibodies, can also have profound ocular features, including uveitis $(17,18)$. Although aortitis is an uncommon feature of the ANCA-associated vasculitides, it has been reported both before and after the onset of more overt small vessel disease (19). Although several case reports have described concurrent ocular involvement (episcleritis, sclerokeratitis, conjunctivitis) and aortitis in the ANCA- associated vasculitides, none have described concurrent uveitis (19-22). However, our patient did not have any of the classic features to suggest a primary diagnosis of rhinogenic granulomatosis with necrotizing angiitis, microscopic polyangiitis or the Churg-Strauss syndrome, including a lack of sinus or lung lesions, refractory asthma, abnormal renal function, eosinophilia or a positive ANCA serology (23). 
Takayasu arteritis is a large vessel vasculitis in which the predominant feature and telltale sign is pulselessness. Pathologic studies and autopsy series revealed the presence of granulomatous inflammatory lesions in the media, adventitia, and throughout the vasa vasorum of the aorta and its main tributaries. This inflammation leads to intimal thickening, vessel stenosis, aneurysm formation, and vascular compromise. Despite its status as the prototypic large vessel vasculitis, Takayasu arteritis was originally described in the ophthalmology, and not the rheumatology, literature (24). Several more cases were subsequently described, after which the pathologic finding of panarteritis was first noted in 1940 (25). These early descriptions focused on the shared characteristics of fever, pulselessness, aneurysmal formation, and visual loss (25). Visual impairment was attributed to a lack of blood supply to the internal carotid artery resulting in low pressure flow to the retina, producing the arteriovenous anastomoses observed by Dr. Takayasu (25). Other forms of ocular pathology are also described in Takayasu arteritis, including reports of uveitis in pediatric and adult patients (Tables $2 a+2 b)(9,26-32)$. One such case is remarkably similar to the present report, occurring in a young African-American woman who initially presented with uveitis and four years later developed arthralgias, weight loss, elevated inflammatory markers and pulselessness (29).

In a retrospective cohort of 75 patients with Takayasu arteritis from the Cleveland Clinic, $12 \%$ presented with visual aberrations (blurring, scotoma, or diplopia). However, uveitis was not noted in this series (33). In a retrospective cohort of 45 patients in Ankara, Turkey from 1973 to 2003,10\% were reported as having visual symptoms including one patient with documented uveitis (26). In addition, among a cohort of 60 patients with Takayasu arteritis followed at the NIH from 1970 to 1990 , there were two patients who presented with uveitis (9). The first patient developed unilateral anterior uveitis at the age of 4 and progressed 9 years later to have stenotic lesions of the aortic arch. This patient had a synovial biopsy of the wrist which showed noncaseating granulomas, interpreted as being indicative of sarcoidosis. A second patient developed bilateral uveitis and hilar adenopathy which on biopsy showed noncaseating graulomas. Angiography, however, showed extensive stenotic lesions consistent with a large vessel vasculitis. Both patients were AfricanAmerican women (9).

In our case, we believe that the findings of bilateral uveitis, persistent fevers, elevated inflammatory markers, and asymmetric blood pressure are most consistent with a diagnosis of Takayasu arteritis. In retrospect, her adult-onset headaches in the preceding two years may have been an early symptom of the large vessel vasculitis. Headaches are described in $28-42 \%$ of patients with Takayasu arteritis $(9,13)$. As mentioned above, our patient did not have lymphadenopathy, diarrhea, hematochezia, malabsorption, glomerulonephritis or lung disease that would suggest the other above-mentioned granulomatous processes. We acknowledge the unusual finding of a left arm blood pressure that was unable to be auscultated in the presence of a preserved palpable brachial pulse. However, diffuse circumferential thickening of the aortic arch and left subclavian artery were noted on her initial MRI scan. Moreover, invasive hemodynamic pressure monitoring demonstrated a pressure gradient between the left and right upper extremities which might have accounted for this discrepancy. A unique feature of this case is the relatively short time interval between the development of uveitis and the notable discovery of aortitis, prior to the development of significant vascular stenosis or hemodynamic compromise. In previous case reports, the onset of uveitis was 2-9 years prior to the discovery of vascular abnormalities (pulselessness or significant stenoses) or occurred concomitantly with the onset of a significant vascular event $(9,29)$.

Imaging played a critical role in the diagnosis and long term follow-up of this patient. CT scan images revealed the initial diagnostic finding of carotid arterial thickening; however, in 
the setting of an FUO, the utility of radiologic imaging to uncover the diagnosis of systemic vasculitis has been recently demonstrated (34). In one study of 67 such patients, a $31 \%$ increase in the diagnosis of systemic vasculitis was achieved by inclusion of MR imaging of the aorta and its major branches in the diagnostic algorithm (34).

Once the diagnosis of Takayasu arteritis was made, our patient responded quickly to therapy with steroids ( $1 \mathrm{mg} / \mathrm{kg} /$ day dosing) and mycophenolate mofetil (MMF). MMF has demonstrated efficacy as a steroid-sparing agent in the management of both Takayasu arteritis and chronic uveitis (35-37). It was selected as our first-line agent as it does not adversely impact fertility or require dosing by assay of drug levels; overall, MMF has a favorable side effect profile. Other therapeutic options included consideration of azathioprine, methotrexate and cyclophosphamide. Our patient defervesced and had complete normalization of inflammatory markers within one week. Prednisone was tapered by approximately $10 \mathrm{mg}$ per month; however, below a nadir dose of $10 \mathrm{mg}$ daily, the patient experienced the return of systemic symptoms of malaise, arthralgias and corresponding increases in ESR and CRP levels. Given the inability to wean the steroid medication further, notwithstanding continued use MMF at a total daily dose of $3000 \mathrm{mg}$, the MMF was then switched to etanercept, an inhibitor of tumor necrosis factor alpha, with improved disease control $(38,39)$.

In summary, our patient demonstrates and underscores the interesting intersection of inflammatory ocular disease with the inflammatory vascular diseases in disorders with granulomatous infiltrates. Aortitis may be a challenging diagnosis to make, as with our patient, when systemic symptoms present before significant stenosis and resultant hemodynamic changes occur. A large vessel vasculitis could easily be overlooked on routine laboratory screening and radiologic evaluation, without a dedicated imaging study to assess for arterial wall edema, structural compromise and luminal narrowing. Each of the diseases considered in our patient, Takayasu arteritis, sarcoidosis, Crohn's disease, and rhinogenic granulomatosis with necrotizing angiitis, seem very different at first glance. However, they share the overlapping features of aortitis and uveitis. The search for common pathophysiologic mechanisms among these diseases is an important and exciting area of ongoing investigation.

\section{References}

1. Jakob E, Reuland MS, Mackensen F, Harsch N, Fleckenstein M, Lorenz HM, et al. Uveitis subtypes in a German interdisciplinary uveitis center--analysis of 1916 patients. J Rheumatol. 2009 Jan; 36(1):127-36. [PubMed: 19132784]

2. Thorne, JE.; Jabs, DA. The eye in rheumatic disease. In: Hochberg, MC.; Silman, AJ.; Smolen, JS.; Weinblatt, ME.; Weisman, MH., editors. Rheumatology. 4. Philadelphia: Elsevier; 2008. p. 261-268.

3. Rosenbaum JT. An algorithm for the systemic evaluation of patients with uveitis: Guidelines for the consultant. Semin Arthritis Rheum. 1990 Feb; 19(4):248-57. [PubMed: 2181671]

4. Kiss S, Damico FM, Young LH. Ocular manifestations and treatment of syphilis. Semin Ophthalmol. 2005 Jul-Sep; 20(3):161-7. [PubMed: 16282150]

5. Roberts WC, Ko JM, Vowels TJ. Natural history of syphilitic aortitis. Am J Cardiol. 2009 Dec 1; 104(11):1578-87. [PubMed: 19932796]

6. Centers for Disease Control and Prevention. Sexually transmitted diseases surveillance 2006, national profile [homepage on the Internet]. Atlanta, GA: U.S. Department of Health and Human Services; 2006. Available from: http://www.cdc.gov/std/stats06/syphilis.htm

7. Wegener F. About a peculiar rhinogenic granulomatosis with marked involvement of the arterial system and kidneys. Beitr Pathol Anat Allg Pathol. 1939; 102:30-68. [in German]. 
8. Weiler V, Redtenbacher S, Bancher C, Fischer MB, Smolen JS. Concurrence of sarcoidosis and aortitis: Case report and review of the literature. Ann Rheum Dis. 2000 Nov; 59(11):850-3. [PubMed: 11053059]

9. Kerr GS, Hallahan CW, Giordano J, Leavitt RY, Fauci AS, Rottem M, et al. Takayasu arteritis. Ann Intern Med. 1994 Jun 1; 120(11):919-29. [PubMed: 7909656]

10. Yilmaz S, Aydemir E, Maden A, Unsal B. The prevalence of ocular involvement in patients with inflammatory bowel disease. Int J Colorectal Dis. 2007 Sep; 22(9):1027-30. [PubMed: 17262200]

11. Talbot RW, Heppell J, Dozois RR, Beart RW Jr. Vascular complications of inflammatory bowel disease. Mayo Clin Proc. 1986 Feb; 61(2):140-5. [PubMed: 3080643]

12. Reny JL, Paul JF, Lefebvre C, Champion K, Emmerich J, Bletry O, et al. Association of Takayasu's arteritis and Crohn's disease. Results of a study on 44 Takayasu patients and review of the literature. Ann Med Interne (Paris). 2003 Mar; 154(2):85-90. [PubMed: 12746644]

13. Hall S, Barr W, Lie JT, Stanson AW, Kazmier FJ, Hunder GG. Takayasu arteritis. A study of 32 North American patients. Medicine (Baltimore). 1985 Mar; 64(2):89-99. [PubMed: 2858047]

14. Todini AR, Heinzmann MM, Antignani PL, Paiella ML. Association between Takayasu's arteritis and Crohn's disease in two young women: Case reports. J Mal Vasc. 1999 Dec; 24(5):373-6. [PubMed: 10642650]

15. Yazdanyar S, Weischer M, Nordestgaard BG. Genotyping for NOD2 genetic variants and Crohn disease: A metaanalysis. Clin Chem. 2009 Nov; 55(11):1950-7. [PubMed: 19713276]

16. Ogura Y, Bonen DK, Inohara N, Nicolae DL, Chen FF, Ramos R, et al. A frameshift mutation in NOD2 associated with susceptibility to Crohn's disease. Nature. 2001 May 31; 411(6837):603-6. [PubMed: 11385577]

17. Levine SM, Racusen L, Gelber AC. Seeing red. Am J Med. 2006 Feb; 119(2):123-4. [PubMed: 16443411]

18. Haynes BF, Fishman ML, Fauci AS, Wolff SM. The ocular manifestations of Wegener's granulomatosis. Fifteen years experience and review of the literature. Am J Med. 1977 Jul; 63(1): 131-41. [PubMed: 327802]

19. Chirinos JA, Tamariz LJ, Lopes G, Del Carpio F, Zhang X, Milikowski C, et al. Large vessel involvement in ANCA-associated vasculitides: Report of a case and review of the literature. Clin Rheumatol. 2004 Apr; 23(2):152-9. [PubMed: 15045631]

20. Nakabayashi K, Kamiya Y, Nagasawa T. Aortitis syndrome associated with positive perinuclear antineutrophil cytoplasmic antibody: Report of three cases. Int J Cardiol. 2000 Aug 31.75(Suppl 1):S89, 94. discussion S95-7. [PubMed: 10980343]

21. Sieber SC, Cuello B, Gelfman NA, Garfinkel HB. Pulmonary capillaritis and glomerulonephritis in an antineutrophil cytoplasmic antibody-positive patient with prior granulomatous aortitis. Arch Pathol Lab Med. 1990 Dec; 114(12):1223-6. [PubMed: 2252417]

22. Blockmans D, Baeyens H, Van Loon R, Lauwers G, Bobbaers H. Periaortitis and aortic dissection due to Wegener's granulomatosis. Clin Rheumatol. 2000; 19(2):161-4. [PubMed: 10791632]

23. Gelber, AC. Classification and epidemiology of inflammatory vascular disease. In: Hochberg, MC.; Silman, AJ.; Smolen, JS.; Weinblatt, ME.; Weisman, MH., editors. Rheumatology. 4. Philadelphia; Elsevier: 2008. p. 1489-1498.

24. Takayasu M. A case with peculiar lesions of the retinal central vessels. Acta Soc Opthal Jpn. 1908(12):554-5.

25. Shimizu K, Sano K. Pulseless disease. Journal of neuropathology and clinical neurology. 1951; 1:37-57.

26. Ureten K, Ozturk MA, Onat AM, Ozturk MH, Ozbalkan Z, Guvener M, et al. Takayasu's arteritis: Results of a university hospital of 45 patients in Turkey. Int J Cardiol. 2004 Aug; 96(2):259-64. [PubMed: 15262043]

27. Soto ME, Espinola N, Flores-Suarez LF, Reyes PA. Takayasu arteritis: Clinical features in 110 Mexican Mestizo patients and cardiovascular impact on survival and prognosis. Clin Exp Rheumatol. 2008 May-Jun; 26(3 Suppl 49):S9-15. [PubMed: 18799047]

28. Kausman JY, Walker A, Piper S. Acute panuveitis and Takayasu's arteritis. Arch Dis Child. 2003 Oct; 88(10):938-9. [PubMed: 14500319] 
29. Jolly M, Curran JJ. Infliximab-responsive uveitis and vasculitis in a patient with Takayasu arteritis. J Clin Rheumatol. 2005 Aug; 11(4):213-5. [PubMed: 16357759]

30. Kaliaperumal S, Gupta A, Sengupta S, Srinivasan R. Unilateral hemorrhagic keratouveitis as the initial presentation of Takayasu's arteritis. Indian J Ophthalmol. 2007 Sep-Oct; 55(5):397-8. [PubMed: 17699960]

31. Becker RW, Sohn RL, Poulik JM, Berguer R. Takayasu's arteritis presenting as uveitis in a 5-yearold girl. Ann Vasc Surg. 2005 Mar; 19(2):258-62. [PubMed: 15776305]

32. McDonald MA, Ojaimi E, Favilla I. Anterior uveitis in a child with Takayasu's arteritis. Clin Experiment Ophthalmol. 2004 Jun; 32(3):336-9. [PubMed: 15180852]

33. Maksimowicz-McKinnon K, Clark TM, Hoffman GS. Limitations of therapy and a guarded prognosis in an American cohort of Takayasu arteritis patients. Arthritis Rheum. 2007 Mar; 56(3): 1000-9. [PubMed: 17328078]

34. Wagner AD, Andresen J, Raum E, Lotz J, Zeidler H, Kuipers JG, et al. Standardised work-up programme for fever of unknown origin and contribution of magnetic resonance imaging for the diagnosis of hidden systemic vasculitis. Ann Rheum Dis. 2005 Jan; 64(1):105-10. [PubMed: 15608307]

35. Daniel E, Thorne JE, Newcomb CW, Pujari SS, Kacmaz RO, Levy-Clarke GA, et al. Mycophenolate mofetil for ocular inflammation. Am J Ophthalmol. 2010 Mar; 149(3):423, 32.e12. [PubMed: 20042178]

36. Shinjo SK, Pereira RM, Tizziani VA, Radu AS, Levy-Neto M. Mycophenolate mofetil reduces disease activity and steroid dosage in Takayasu arteritis. Clin Rheumatol. 2007 Nov; 26(11):18715. [PubMed: 17332971]

37. Daina E, Schieppati A, Remuzzi G. Mycophenolate mofetil for the treatment of Takayasu arteritis: Report of three cases. Ann Intern Med. 1999 Mar 2; 130(5):422-6. [PubMed: 10068416]

38. Hoffman GS, Merkel PA, Brasington RD, Lenschow DJ, Liang P. Anti-tumor necrosis factor therapy in patients with difficult to treat Takayasu arteritis. Arthritis Rheum. 2004 Jul; 50(7): 2296-304. [PubMed: 15248230]

39. Molloy ES, Langford CA, Clark TM, Gota CE, Hoffman GS. Anti-tumour necrosis factor therapy in patients with refractory Takayasu arteritis: Long-term follow-up. Ann Rheum Dis. 2008 Nov; 67(11):1567-9. [PubMed: 18677012] 


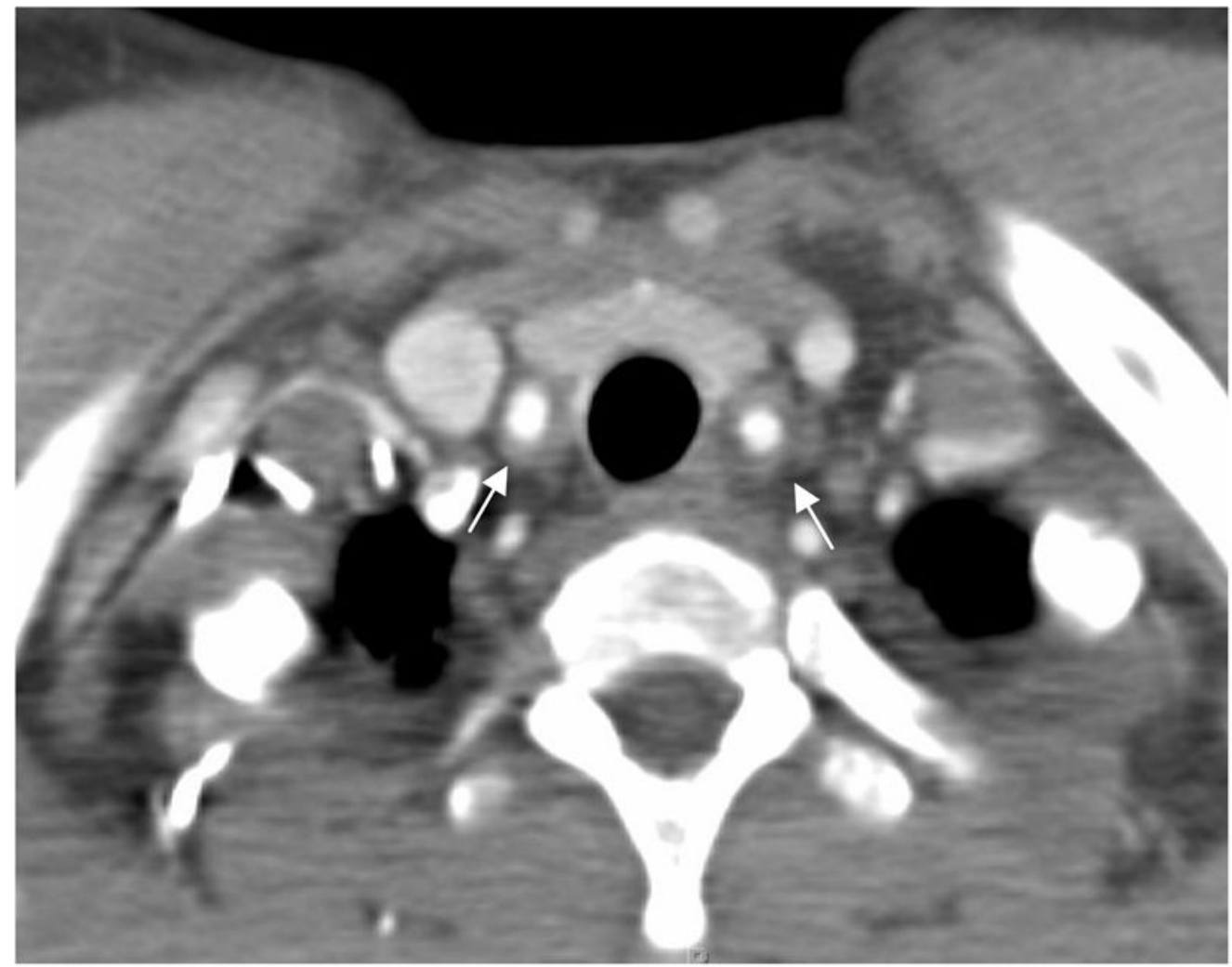

Figure 1.

CT scan with IV contrast demonstrating marked bilateral circumferential thickening of the common carotid arteries (arrows). 


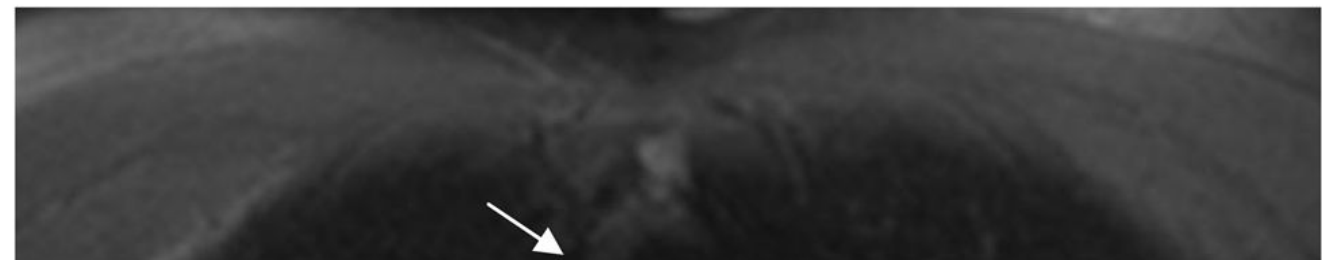

Figure 2.

Axial T1-weighted MRI with fat-suppression sequence demonstrates diffuse circumferential thickening of the aortic arch (arrows). 


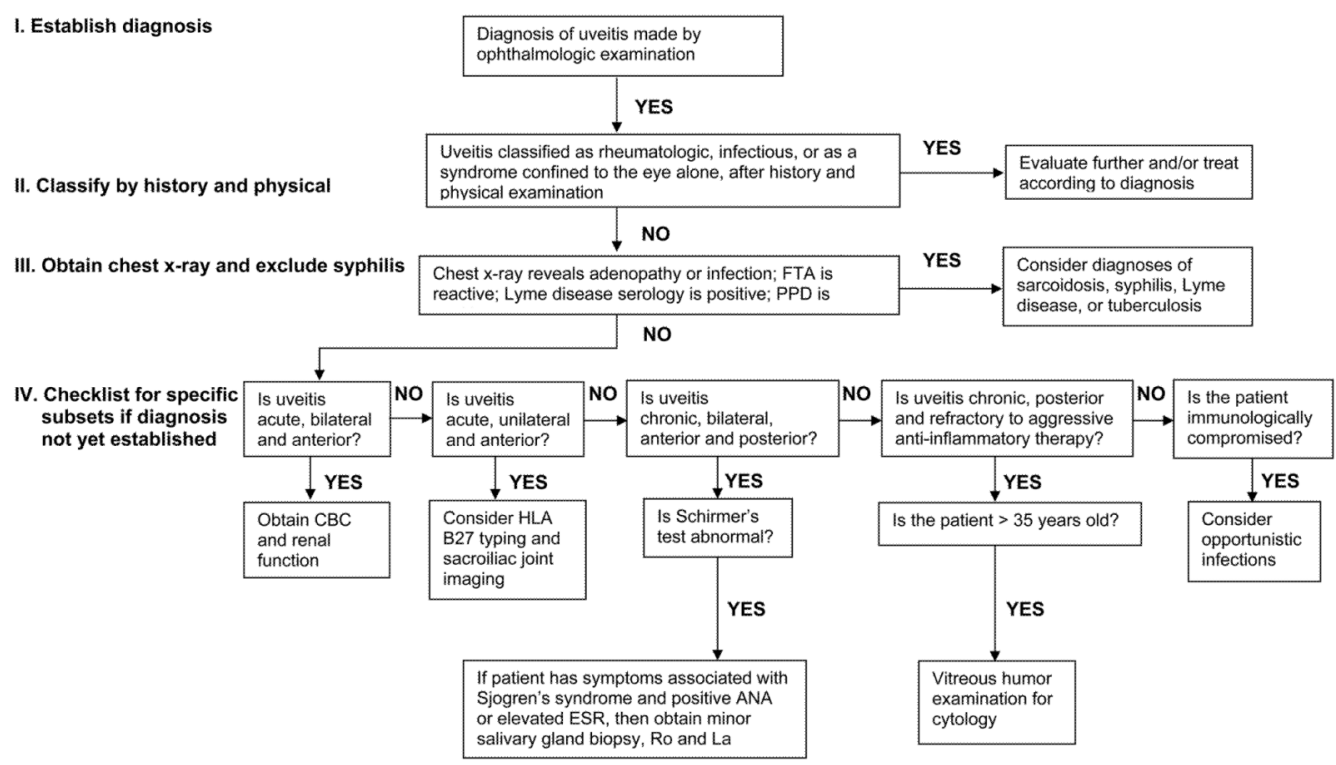

Figure 3.

Algorithm to identify an underlying etiology in the evaluation of uveitis. (Adapted from Reference 3) 


\section{Table 1}

Differential Diagnosis for Co-Occurrence of Uveitis and Aortitis

\begin{tabular}{ll}
\hline Infectious: & Vasculitis: \\
Lyme disease & Bechet's syndrome \\
Syphillis & Takayasu arteritis \\
Tuberculosis & Wegener's granulomatosus \\
Arthritis: & Other: \\
Spondyloarthropathy & Crohn's disease \\
- Ankylosing spondylitis & Sarcoidosis \\
\hline
\end{tabular}




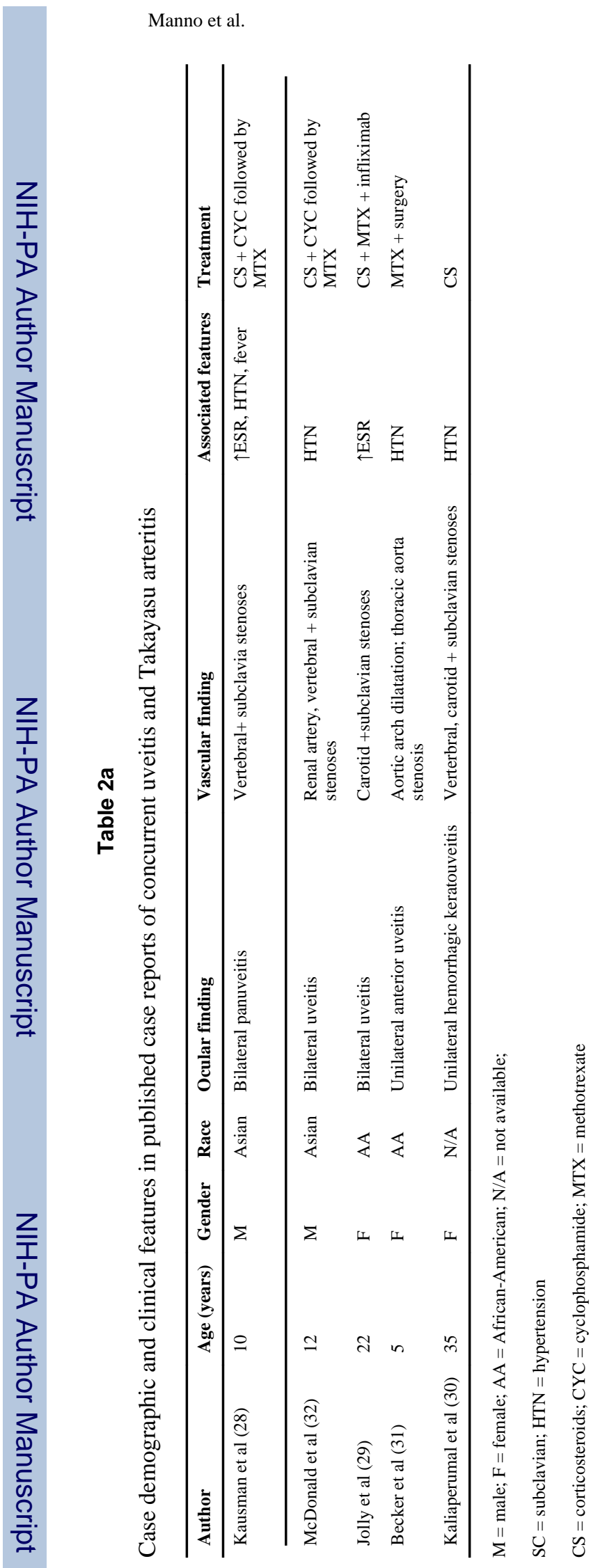

Semin Arthritis Rheum. Author manuscript; available in PMC 2012 February 1. 


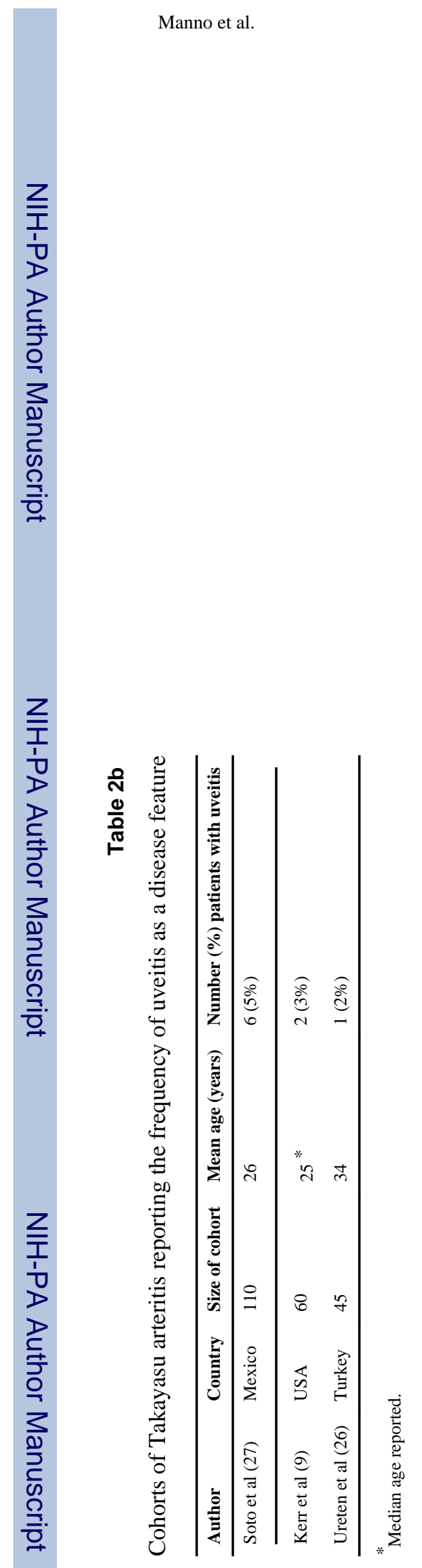

Semin Arthritis Rheum. Author manuscript; available in PMC 2012 February 1. 